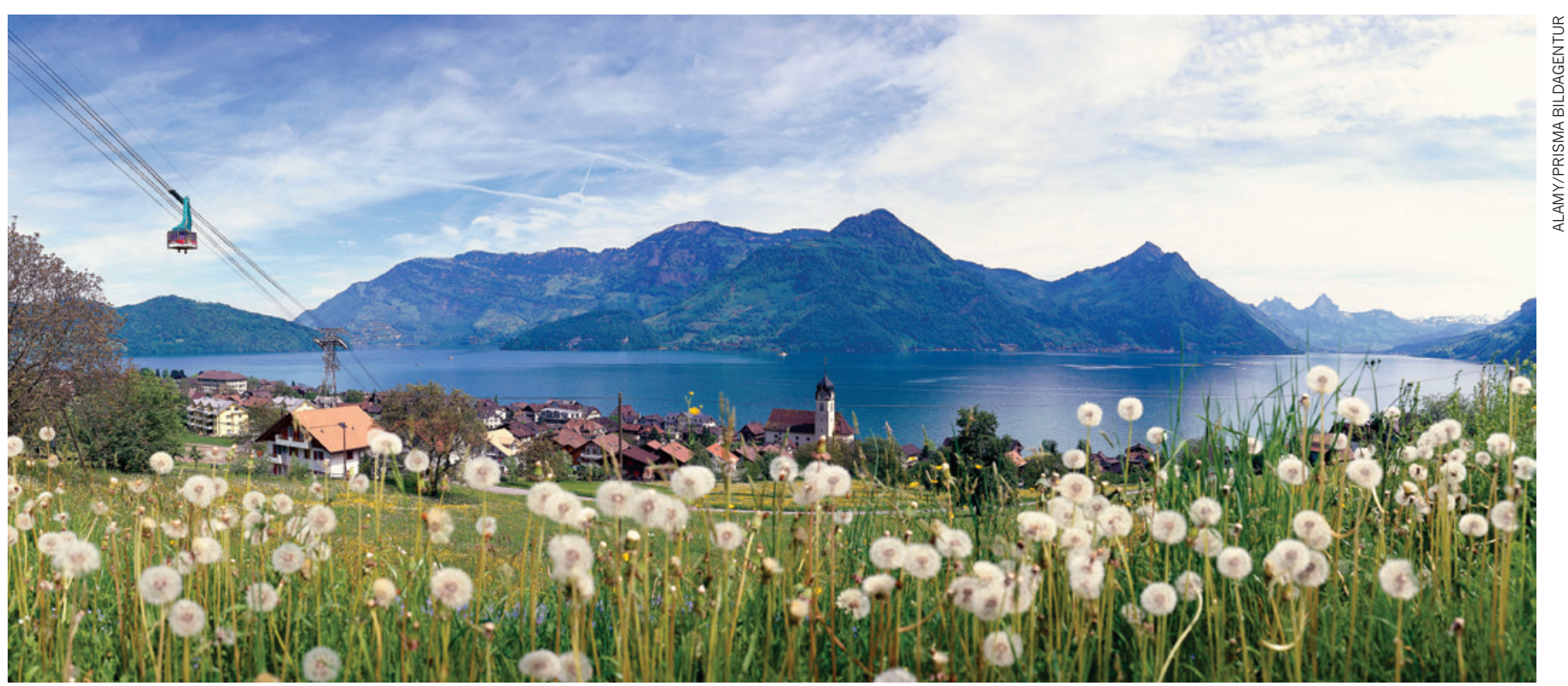

The area surrounding Lake Lucerne in Switzerland experiences a magnitude- 6 earthquake about once every 1,000 years.

NATURAL HAZARDS

\title{
Switzerland braces for Alpine lake tsunami
}

\section{Authorities in Swiss canton blaze a trail by factoring the risk into hazard planning.}

\section{BY LAURA SPINNEY}

$\mathrm{T}$ The land of chocolate and clocks could soon be known for something quite different: tsunamis. Authorities in Nidwalden, a canton in landlocked Switzerland, are factoring the risk of a tsunami in Lake Lucerne into their hazard plans. It is the first official acknowledgement of such a threat in Europe's Alpine region - and comes in step with findings that the risk of tsunamis in the area, which is home to around 13 million people, is much higher than previously thought.

Most tsunamis occur in the ocean but they can also occur in enclosed bodies of water, when underwater sediments shift as a result of an earthquake, falling rocks or underlying instability. The hazard that such events pose is outsized. "The same source placed inside a lake can have a bigger impact than along the coast of an open ocean," says Hermann Fritz, who studies tsunamis at the Georgia Institute of Technology in Atlanta. A tsunami at Lake Yanawayin in Peru in 1971 is thought to have killed 400-600 people.

Although not as seismically active as Peru or Japan, the Alps do experience earthquakes from time to time: one as strong as magnitude 6 occurs roughly every millennium around Lake Lucerne, for instance.

The issue of tsunamis in Alpine lakes grabbed the spotlight two years ago when limnogeologist Katrina Kremer, then at the University of Geneva, Switzerland, and her colleagues reported evidence for a major tsunami in Lake Geneva in AD 563 that had wiped out communities living on its shores ${ }^{1}$.

Kremer, who has since moved to the Swiss Federal Institute of Technology (ETH) in Zurich, has upped the count to five probable tsunamis in Lake Geneva over the past 4,000 years, including another devastating one during the Bronze Age around 3,400 years ago ${ }^{2}$. Her team relied on cores

"Taking such risks into account is quite complicated."

taken by drilling 30 metres into the lakebed. The cores represent 4,000 years' worth of sediment deposition, and show telltale structures of lakebed displacement that could have caused a tsunami. Kremer presented the work on 18 August at a meeting of the International Association of Sedimentologists in Geneva.

The AD 563 event, the largest of the five, occurred when part of a mountain fell onto an unstable underwater delta of the Rhône river, which flows into Lake Geneva (see 'Origin of a wave'). The falling rock forced the collapse of sections of the delta, creating a wave that was 8 metres high when it hit and wiped out the old city of Geneva at the other end of the lake.

The Bronze Age tsunami was 6 metres high, and may provide another example of tsunamirelated devastation in the Lake Geneva region, because it fits with a possible abandonment by lake-shore dwellers. "We think this could explain an occupation gap in early Bronze Age sites on the northern shore of the lake," says Kremer. Albert Hafner, an archaeologist at the University of Bern, finds the hypothesis convincing: "They left their sites for many reasons, but tsunamis may have been one of them."

The episodes add to growing evidence for historical tsunamis in other Alpine lakes, including two events ${ }^{3}$ in Lake Como in northern Italy, in the sixth and twelfth centuries $\mathrm{AD}$, and one in Lake Bourget in the French Alps in 1822. A witness of the 1822 tsunami described the water as "boiling like soup", an effect caused by the release of methane when an earthquake stirs up organic debris in the lake.

In the past decade, a history of tsunamis has also emerged for Lake Lucerne. Research by Flavio Anselmetti, a geologist at the University of Bern, and his colleagues reveals ${ }^{4}$ that the lake experienced two tsunamis in the seventeenth century. The first, in 1601, reached 5 metres in 


\section{ORIGIN OF A WAVE}

Tsunamis in Alpine lakes might be caused by rockslides,

earthquakes or the spontaneous collapse of unstable river

deltas. A digital reconstruction shows an area of Lake Geneva's

present-day lakebed. The corresponding region collapsed in

AD 563, triggering a wave that propagated across the lake and

wiped out Geneva.

\section{Underwater sediment}

deposited by the Rhône river flowing into Lake Geneva.

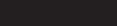
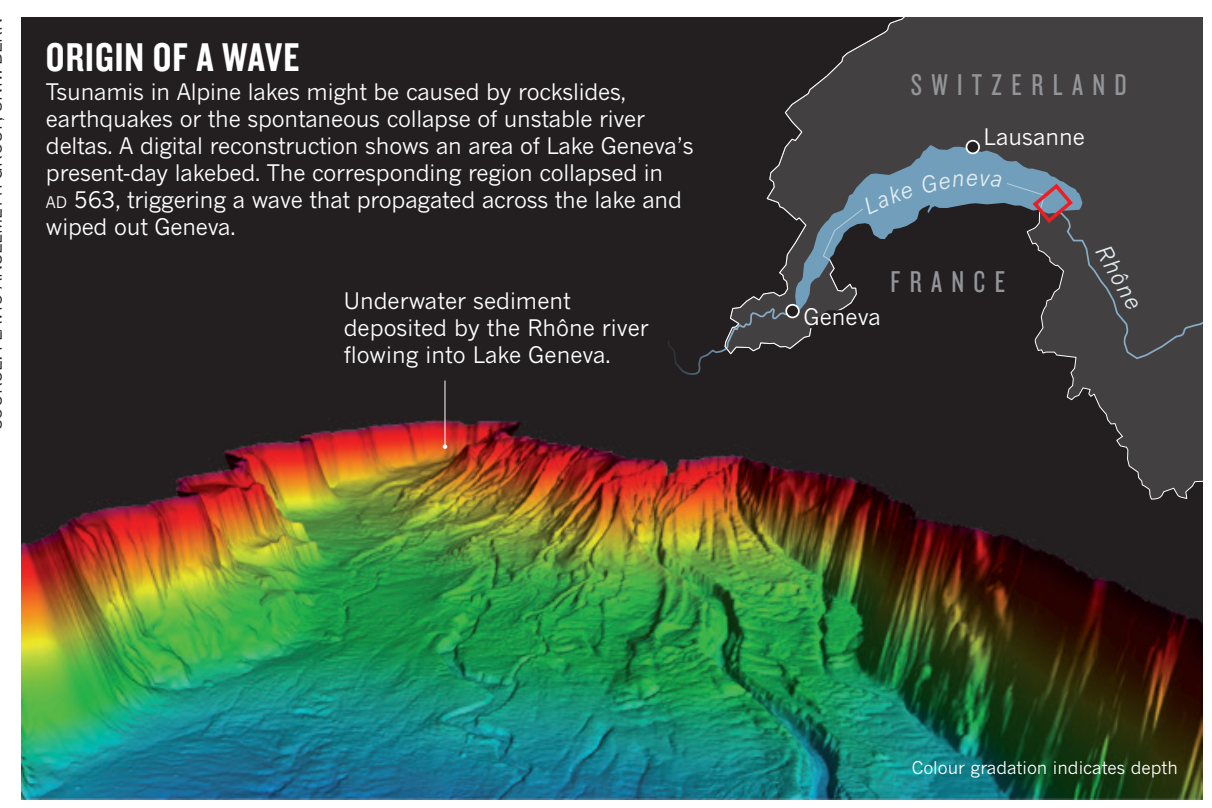

height. The amount of sediment on some of the lake's underwater slopes has since increased, and a strong earthquake could easily dislodge it, triggering a tsunami, says Anselmetti.

Nidwalden, which borders the lake, has now commissioned Anselmetti's team to assess the likelihood of such an event for different scenarios, including earthquakes of various strengths or a rockslide - as well as the probable effect on the surrounding land. Aided by geological data and computer simulations, they plan to create maps of the inundation in each scenario. The authorities will use the charts to draw up evacuation plans and to guide future construction.

Although the risk of a tsunami in Lake Lucerne seems remote, the possibility is real enough that insurers might want to know about it, says Anselmetti. Underwriters typically consider events that might occur within the next 500 years worth insuring against, and it has now been more than 400 years since the most recent magnitude- 6 earthquake at Lake Lucerne.

Nidwalden is, for now, blazing a lonely trail with such plans. Conditions differ across regions, provoking varying reactions to the threat of Alpine tsunamis. With many more people living on its shores and different physical and geographical factors at play, a tsunami in Lake Geneva could have more devastating effects than one in Lake Lucerne, but is less likely to occur in the next 500 years. "Taking such risks into account is quite complicated," says Jacques Martelain, geologist for the canton of Geneva. "What should we do, knock the city down and rebuild it elsewhere? We could take measures to protect the built-up lake shore, but that seems disproportionate."

Other regions may yet follow in Nidwalden's footsteps. Kremer's latest work shows that smaller, but still damaging, tsunamis occur more frequently than bigger ones. When it comes to crucial infrastructure, insurers deem periods longer than 500 years worth planning for: an event that poses a threat to nuclearpower plants, for instance, need recur only every 10,000 years to be considered.

Lives can be saved if people are trained to respond to a tsunami, but until earthquake prediction improves, planning efforts will not be able to mitigate damage completely. "The population," says Fritz, "must learn to live with the hazard to some extent." "

1. Kremer, K., Simpson, G. \& Girardclos, S. Nature Geosci. 5, 756-757 (2012).

2. Kremer, K. et al. Earth Planet. Sci. Lett. 385, 28-39 (2014).

3. Fanetti, D., Anselmetti, F. S., Chapron, E., Sturm, M. \& Vezzoli, L. Palaeogeogr. Palaeoclimatol. Palaeoecol. 259, 323-340 (2008).

4. Schnellmann, M., Anselmetti, F. S., Giardini, D. \& Mckenzie, J. A. Eclogae Geol. Helv. 99, 409-428 (2006).

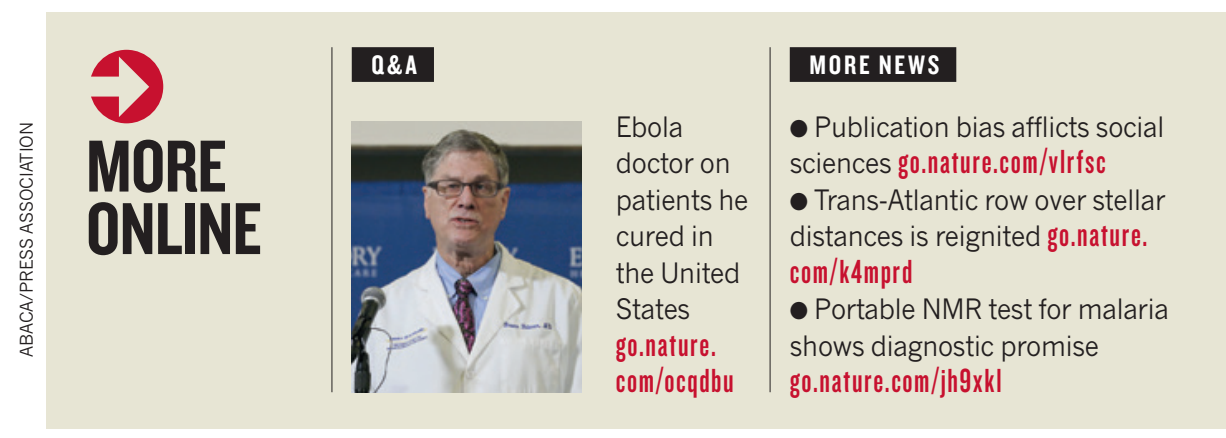

